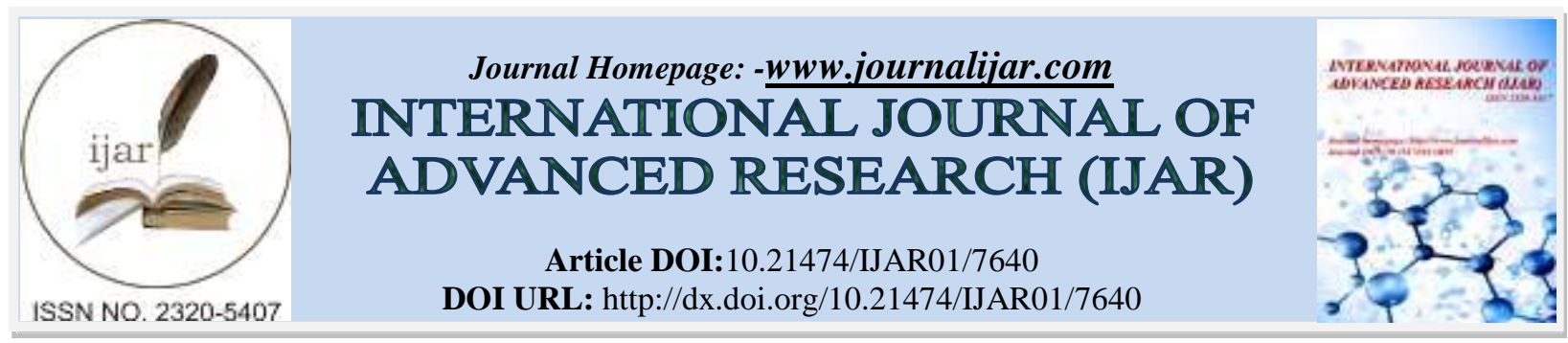

RESEARCH ARTICLE

\title{
ASSESSMENT OF PREGNANT WOMEN'S KNOWLEDGE AND PRACTICE TO PREVENT TOXOPLASMOSIS INFECTION IN MALLAWY CITY MINIA GOVERNORATE.
}

Khaled Hussein Mohamed I. El-dessouki ${ }^{1}$ and Wael M. Abd ElGhany ${ }^{2}$.

1. Assistant Professor of community medicine. Faculty of medicine-Minia University.

2. Assistant Professor of Tropical medicine. Faculty of medicine-Minia University.

\section{Manuscript Info}

Manuscript History

Received: 02 July 2018

Final Accepted: 04 August 2018

Published: September 2018

Keywords:-

toxoplasmosis, knowledge, practice, pregnant women, Minya

\section{Abstract}

Background:- Toxoplasma gondii is a congenital infectious agent which causes severe clinical outcomes in fetus and newborns. The lifethreatening parasitic disease is preventable by measures related to lifestyle during pregnancy.

The aim of the study: is to assess the knowledge about toxoplasmosis and practices that can prevent it among the pregnant women.

Methods: Total of 200 pregnant women from Mallawy city Minia governorate were included in the study to determine their knowledge and practices on Toxoplasma infection. A questionnaire to evaluate general information and knowledge on risks factors, time of infection, symptoms, prevention knowledge and behavior regarding Toxoplasmosis.

Results:- Mainstream of these pregnant women were in their age group of 20-29 years (50.9\%), completed secondary level of education $(51.7 \%)$, in their second trimester of pregnancies $(38.1 \%)$, non-parous $(36.6 \%)$, and had no history of abortion $(90.4 \%)$. According to this study, only $11 \%$ of these pregnant women had read, heard, or seen information regarding toxoplasmosis and 3.5\% of them were aware of being tested for the infection. A small percentage of these pregnant women knew that $\mathrm{T}$. gondii were shed in the feces of infected cats $(19.4 \%)$ and sometimes found in the raw or undercooked meat (11. $0 \%$ ). There was $16.1 \%$ of pregnant women included in this study knew that toxoplasmosis is caused by an infection.

Conclusion:- Demographic characteristics such as age group, level of education, pregnancy term, and a number of children of the pregnant women showed significant association with their responses toward questions related to prevention knowledge and behavior. Health education on Toxoplasma infection and preventive practices should be presented to reproductive age women and pregnant women. This information could help to reduce the transmission of Toxoplasma gondii infection during pregnancy

Copy Right, IJAR, 2018, All rights reserved. 


\section{Introduction:-}

Toxoplasmosis affects almost a third of the world population. In adults, it is asymptomatic, while having an important manifestation in children- infected by placental transmission. This parasitic infection can be transmitted by ingestion of Toxoplasma oocysts contaminated fruits and vegetables or unclean water, through blood transfusion, and by receiving an organ transplant. Exposures to contaminated feces by cleaning cat's litter, gardening, or handling contaminated soils. The prenatal period is an important chance, requiring actions in pregnant women's care, to prevent the diseases. Toxoplasma Infection during pregnancy can lead to severe illness in the fetus and infant including central nervous system and ocular disease, and even death [1]. According to local and regional studies, the Center for Diseases Control and Prevention (CDC) estimates that there are 400-4000 cases of congenital toxoplasmosis per year[2] and that Toxoplasma gondii infection is the third leading cause of foodborne deaths in the US[3]. Population-based studies in the US have shown that most (85\%) pregnant women are susceptible to infection with T. gondii [4]. Many congenital T. gondii infections acquired during gestation are preventable by simple precautions during pregnancy. These precautions include fully cooking meat, not ingesting uncooked or undercooked meat and not ingesting soil or water contaminated with cat feces, like soil from sand boxes and cat litter boxes, or soil on raw fruits and vegetables [2]. This study was done in order to determine the pregnant women knowledge about toxoplasmosis and the practices that prevent infection, of congenital toxoplasmosis.

\section{Study Subjects \&Methods:-}

To assess pregnant women's knowledge and behavior towards toxoplasma infection we developed a questionnaire for this study. The questions covered pregnant women' knowledge of preventive practices in general, risk behavior, and sources of their information. Questions were based on preceding studies $[\underline{3}, \underline{4}, \underline{5}, \underline{6}, \underline{7}, \underline{8}, \underline{17}, \underline{26}, \underline{27}, \underline{28}$. The questionnaire covered knowledge about the disease and preventive practices. The second section focused on the actual behavior of pregnant women to prevent this infection during their pregnancy.

This cross-sectional study took place in Mallawy medical center which is a primary health care center. A sample of 200 pregnant women was taken from the pregnant women attending for antenatal care in Mallawy medical center. The study took place between June 2016 and September 2016. The study protocol of the study was approved by the Medical Ethics Committee of the Minya University. The participation in the study was voluntary after verbal consent and they could withdraw at any time. Privacy and secrecy were guaranteed. Inclusion criteria are pregnant women in any gestational periods, in any age groups and given verbal consent to participate in this study. Demographic information and questions related to general knowledge about toxoplasmosis risk factors, symptoms, and timing of infection, prevention knowledge, and preventive behavior. Data with qualitative variables were expressed as frequency and percentage.

Demographic and pregnancy-related data including age, educational level, number of pregnancies experienced, residence, planned or unplanned pregnancy and folic acid use was obtained. The gestational age of the pregnant women was divided into first or second trimester versus the third trimester, because of small numbers of pregnant women who were in their first trimester. Finally, the number of pregnancies a respondent experienced was categorized into primigravida or multigravida.

This study measures knowledge about preventive practices and risk behavior concerning toxoplasmosis of pregnant women. Frequency distributions for the questionnaire items on knowledge of preventive practices and risk behavior were calculated. The data analysis was done by using statistical software package SPSS version 19.

\section{Results:-}

The total number of pregnant women was 200 pregnant women who participated in the study and completed the questionnaire on toxoplasmosis between June 2016 and September 2016.

Pregnant women were more likely to have a high education $(57 \%)$. Other demographic characteristics of the study population are presented in (Table1). Pregnant women majority, 75\% $(n=150)$ had heard, read or seen some information about toxoplasmosis. Of these, the majority reported having heard about the infections from their healthcare provider or read about these in newspapers or on the Internet (Table 2). Percentages do not sum to $100 \%$, because multiple answers were accepted. Awareness about prevention of toxoplasma infection varied by topic this showed in Table 3. In terms of preventing toxoplasmosis, pregnant women were most likely to correctly indicate that avoiding contact with cats $(77.5 \%)$ and direct contact with soil $(74 \%)$ were methods to prevent toxoplasmosis in 
pregnancy. Almost half of the pregnant women knew that not eating improperly cooked meat (48.5\%) and thoroughly washing and peeling fruits and vegetables (48.5\%) are ways to prevent toxoplasmosis.

Some pregnant women were unsure about the answers Such as, $73.5 \%$ of the pregnant women were unsure whether removing pet animals from home would prevent toxoplasmosis Regarding toxoplasmosis, 9.5\% of the pregnant women answered all six statements correctly and $20.0 \%$ answered none of the statements correctly; the median knowledge score was 4.0 .

The median knowledge scores per characteristic of the pregnant women shown in (Table 1). A higher median knowledge score for preventive practices for toxoplasmosis was associated with a higher education level.

This study compared pregnant women risk behavior during their current pregnancy with their knowledge about each corresponding preventive practice (Table 4). The reported risk behavior by pregnant women was most often associated with their knowledge of preventive practices of toxoplasmosis. Although only $48.5 \%$ of the pregnant women knew that eating improperly cooked meat increases the risk for a toxoplasmosis infection, most of them did not eat this during pregnancy $(91.5 \%)$. Risk behavior is defined as having done it at least once during their current pregnancy.

This study showed no differences in testified risk behavior between pregnant women who knew that avoid eating improperly cooked meat, eating unwashed fruits and vegetables and direct contact with plant soil was a preventive practice for toxoplasmosis and pregnant women who had incorrect or no knowledge about these preventive practices. We did not find a difference in the percentage of pregnant women who undertook a certain risk behavior among pregnant women who received information about toxoplasmosis from their health care professional versus other sources of information.

We examined whether demographic characteristics were correlated with risk behavior towards toxoplasmosis, Of the 200 pregnant women, $59.5 \%$ reported at least one risk behavior for toxoplasmosis.

By using Multivariate logistic regression analysis this study showed that pregnant women who had a high level of education and did not take folic acid during their first trimester of pregnancy were more likely to practice risky behavior during pregnancy associated with toxoplasmosis (Table 5).

\section{Discussion:-}

This cross-sectional observational study concerning knowledge and risk behavior related to toxoplasmosis, infections during pregnancy showed that - while there was inadequate knowledge about preventive practices against this infection - the majority of pregnant women stated that they practiced appropriate behavior to prevent toxoplasmosis. Our study detected both pieces of knowledge about preventive practices and the risk behavior of pregnant women concerning preventable infectious diseases. [이, $\underline{31]}$. This may indicate that the many pregnant women who had taken on a risk behavior were actually not frequent risk takers but had a single exposure. This study indicates that health care professionals play an important role in informing women about preventable infectious diseases as many pregnant women stated that they having received information about toxoplasmosis, from their health care provider. Books, magazines and the Internet were also important sources of information for the pregnant women. Confirmed by other studies, this study revealed lower median knowledge scores for preventive practices for toxoplasmosis among pregnant women who had less formal education, [모 $\underline{7}, \underline{10}]$. Counter to our hypothesis and confirmed by another study []], disease-specific knowledge was not necessarily associated with preventive practices during pregnancy, concerning toxoplasmosis infection. The lack of knowledge was not always associated with risk behavior. Toxoplasmosis Infection during pregnancy is highly associated with eating improperly cooked meat [12]. Only half of the pregnant women demonstrated knowledge of this relationship, but the majority indicated that they avoided the behavior. [33]. Contrarily, although there was an overall good understanding that toxoplasmosis could be prevented by avoiding contact with soil only one-fifth of the pregnant women had a contact with soil during their pregnancy. For six out of the eight included risk behaviors, there were almost no differences in reported risk behaviors among pregnant women who were or were not aware of the preventive practices against toxoplasmosis. Pregnant women with a higher educational level, who did not take folic acid in their first trimester had greater odds to report a risk behavior for toxoplasmosis. These factors indicate that healthcare professionals involved in mother and child care should give more information's to these women about infectious disease prevention. Changing pregnant women behavior depends on several factors, including the perceptions of the threat [34]. Pregnant women 
receive information during their first prenatal visit, including methods to prevent infectious diseases and this increase, awareness and improve the practice. This may indicate that it is more effective for healthcare professionals to inform pregnant women about behaviors and lifestyle habits they should adopt or avoid and that it may not be necessary to give information on specific infectious diseases. It could be helpful to repeat Information on preventive practices during a later stage in pregnancy, then only during the first prenatal visits. These preventive methods concern hygienic behaviors in general. It is important for healthcare professionals to give information on toxoplasmosis prevention to pregnant women as a study in France showed that simple information on basic hygiene measures given to women at the beginning of their pregnancy could significantly reduce the incidence of maternal infection during pregnancy [36, 37]. Pregnant women seemed to properly avoid risk behavior without exactly knowing why they avoid it. This could reflect the use of cognitive shortcuts, where complex tasks are reduced to simpler operations which allows people to make rapid, efficient, but sometimes unreasonable choices [ $\underline{38}$, $\underline{39}$ ]. Some studies suggest that written education is less effective to establish behavioral change than when health care providers inform clients orally about correct behavior $[\underline{40}, \underline{41}, \underline{42}]$. Our study did not find any difference in the occurrence of risk behavior between those who received information on the toxoplasmosis from a healthcare professional and those who received information from other sources.

\section{Conclusion:-}

A considerable part of the pregnant women in this study had never heard of toxoplasmosis or did not know how to avoid it during pregnancy. On the other hand, many pregnant women were properly avoiding risky behaviors, without knowing what they are avoiding. It is important that healthcare providers continue advising pregnant women about lifestyle habits and performances which can prevent toxoplasmosis. Furthermore, other sources of information about the prevention of toxoplasmosis in pregnancy must be complete and adequate. Generally, more attention towards toxoplasmosis prevention is essential to increase the knowledge and adoption of the preventive practices among pregnant women.

Table 1:-Characteristics of pregnant women and median knowledge score to prevent toxoplasmosis infection in Mallawy city Minia governorate between June 2016 and September 2016.

\begin{tabular}{|c|c|c|c|c|}
\hline & \multicolumn{2}{|c|}{ Total } & \multicolumn{2}{|l|}{ Toxoplasmosis } \\
\hline Determinants & $\mathbf{N}^{*}$ & $(\%)$ & Median knowledge score $^{2}$ & p-value $^{3}$ \\
\hline \multicolumn{5}{|l|}{ Age } \\
\hline $17-25$ year & 27 & $(13.5)$ & 4.0 & \multirow[t]{3}{*}{0.27} \\
\hline 26-34 year & 139 & $(69.5)$ & 4.0 & \\
\hline $35-42$ year & 34 & $(17)$ & 4.0 & \\
\hline \multicolumn{5}{|l|}{ Education $^{1}$} \\
\hline Low & 21 & $(10.5)$ & 3.0 & \multirow[t]{3}{*}{$.000^{*}$} \\
\hline Medium & 65 & $(32.5)$ & 4.0 & \\
\hline High & 113 & (57) & 4.0 & \\
\hline $\begin{array}{l}1^{\text {st }} \text { and } 2^{\text {nd }} \text { trimester of } \\
\text { pregnancy }\end{array}$ & 86 & (43) & 4.0 & \multirow[t]{2}{*}{.19} \\
\hline $3^{\text {rd }}$ trimester of pregnancy & 114 & (57) & 4.0 & \\
\hline Primigravidae & 74 & (37) & 4.0 & \multirow[t]{2}{*}{.95} \\
\hline Multigravida & 126 & (63) & 4.0 & \\
\hline $\begin{array}{l}\text { folic acid } \quad \text { intake } \\
\text { in } 1^{\text {st }} \text { trimester }\end{array}$ & 190 & (95) & 4.0 & \multirow[t]{2}{*}{.09} \\
\hline $\begin{array}{l}\text { NO folic acid intake in } \\
1^{\text {st }} \text { trimester }\end{array}$ & 10 & (5) & 3.0 & \\
\hline
\end{tabular}


Table2:-Sources where pregnant women get their information about toxoplasmosis infection in Mallawy city Minia governorate between June 2016 and September 2016.

\begin{tabular}{|l|l|l|}
\hline Source & \multicolumn{2}{l|}{ Toxoplasmosis } \\
\cline { 2 - 3 } & $\mathbf{N}$ & $(\mathbf{\%})$ \\
\hline Healthcare professional & 96 & 48 \\
\hline Internet & 82 & 41 \\
\hline Newspaper, book or magazine & 75 & 37.5 \\
\hline Family or friends & 34 & 17.0 \\
\hline Another source & 9 & 4.5 \\
\hline Radio or television & 6 & 3 \\
\hline I did not see, hear or read anything about this disease & 48 & 24 \\
\hline
\end{tabular}

Percentages do not sum to $100 \%$, because multiple answers were accepted.

Table 3:-Pregnant women's knowledge about preventive practices against toxoplasmosis infection in Mallawy city Minia governorate between June 2016 and September 2016.

\begin{tabular}{|l|l|l|l|l|}
\hline Preventive practices & $\begin{array}{l}\text { Correct } \\
\text { answer }(\%)\end{array}$ & $\begin{array}{l}\text { False } \\
\text { answer (\%) }\end{array}$ & $\begin{array}{l}\text { Don't know } \\
(\%)\end{array}$ \\
\hline \multirow{4}{*}{ Toxoplasmosis } & Avoid direct contact with cat & 77.5 & 0.5 & 21.5 \\
\cline { 2 - 4 } & Proper Cooking of meat & 48.5 & 12.5 & 39.5 \\
\cline { 2 - 4 } & $\begin{array}{l}\text { Washing and peeling fruits and vegetables } \\
\text { before eating. }\end{array}$ & 48.5 & 13.5 & 38.5 \\
\cline { 2 - 4 } & Avoid direct contact with soil & 74.0 & 1.5 & 24.5 \\
\cline { 2 - 4 } & Removing pet cats from your home* & 20.0 & 5.5 & 73.5 \\
\cline { 2 - 4 } & Regular vitamin supplement intake * & 47.5 & 3.5 & 49.5 \\
\hline
\end{tabular}

* False statement.

Table 4:-Risk behavior*; Overall and separately for women with correct and incorrect/no knowledge of preventive practices against toxoplasmosis infection in Mallawy city Minia governorate between June 2016 and September 2016.

\begin{tabular}{|c|c|c|c|c|}
\hline \multicolumn{2}{|l|}{ Risk behavior } & \multirow{2}{*}{\begin{tabular}{|l|} 
Overall \\
$(\%)$
\end{tabular}} & \multirow{2}{*}{$\begin{array}{l}\begin{array}{l}\text { Incorrect/No } \\
\text { knowledge }\end{array} \\
(\%)\end{array}$} & \multirow{2}{*}{$\begin{array}{l}\text { Knowledge } \\
(\%)\end{array}$} \\
\hline & & & & \\
\hline \multirow{4}{*}{$\begin{array}{l}\text { Toxoplasmosis } \\
\mathbf{N}=\mathbf{2 0 0}\end{array}$} & Eat rare or medium cooked meat & 8.5 & 7.5 & 8.5 \\
\hline & Contact with soil & 21.5 & 20.5 & 21.5 \\
\hline & Contact with cat & 4.5 & 1.5 & 5.5 \\
\hline & Eat unwashed raw vegetables or fruits & 46.5 & 50.5 & 42.5 \\
\hline
\end{tabular}

Risk behavior is defined as having done it at least once during their current pregnancy. 
Table 5:-Associations between characteristics of pregnant women and their risk behavior ${ }^{1}$ regarding toxoplasmosis infection in Mallawy city Minia governorate between June 2016 and September 2016.

\begin{tabular}{|l|l|l|l|}
\hline \multicolumn{2}{|l|}{ Toxoplasmosis } & OR (95\% CI) & Adjusted OR (95\% CI) \\
\hline Determinants & Risk behavior (\%) & & \\
\hline Age & & - & \\
\hline 17-25 year & 51.5 & $1.4(1.0-2.0)^{*}$ & \\
\hline 26-34 year & 59.5 & $1.6(1.0-2.4)^{*}$ & \\
\hline $35-42$ year & 62.0 & & - \\
\hline Education & & - & $1.1(0.7-1.6)$ \\
\hline Low & 52.5 & $1.0(0.7-1.6)$ & $1.7(1.1-2.6)^{* *}$ \\
\hline Medium & 52.5 & $1.6(1.1-2.4)^{*}$ & \\
\hline High & 63.5 & - & \\
\hline $\begin{array}{l}1^{\text {st }} \text { and } 2^{\text {nd }} \text { trimester } \\
\text { of pregnancy }\end{array}$ & 60.5 & $0.9(0.7-1.2)$ & \\
\hline $\begin{array}{l}3^{\text {th }} \text { trimester } \\
\text { pregnancy }\end{array}$ & 58.0 & - & $2.7(1.4-5.3)^{* * *}$ \\
\hline Primigravidae & 56.5 & $1.2(0.9-1.5)$ & \\
\hline Multigravida & 60.5 & - & \\
\hline $\begin{array}{l}\text { folic acid intake } \\
\text { in } 1^{\text {st }} \text { trimester }\end{array}$ & 58.5 & $2.3(1.2-4.4)^{*}$ & \\
\hline $\begin{array}{l}\text { NO folic acid intake } \\
\text { in } 1^{\text {st }} \text { trimester }\end{array}$ & 76.0 & & \\
\hline
\end{tabular}

\section{References:-}

1. Ross DS, Jones JL, Lynch MF: Toxoplasmosis, cytomegalovirus, listeriosis, and preconception care. Matern Child Health J. 2006, 10 (Suppl 5): S187-S191.

2. Ross DS, Rasmussen SA, Cannon MJ, Anderson B, Kilker K, Tumpey A, Schulkin J, Jones JL: Obstetrician/gynecologists' knowledge, attitudes, and practices regarding prevention of infections in pregnancy. J Womens Health (Larchmt). 2009, 18 (8): 1187-1193. 10.1089/jwh.2008.1288.

3. Ross DS, Victor M, Sumartojo E, Cannon MJ: Women's knowledge of congenital cytomegalovirus: results from the 2005 HealthStyles survey. J Womens Health (Larchmt). 2008, 17 (5): 849-858. 10.1089/jwh.2007.0523.

4. Jeon J, Victor M, Adler SP, Arwady A, Demmler G, Fowler K, Goldfarb J, Keyserling H, Massoudi M, Richards K, Staras SA, Cannon MJ: Knowledge and awareness of congenital cytomegalovirus among women. Infect Dis Obstet Gynecol. 2006, 2006: 1-7.

5. Jones JL, Ogunmodede F, Scheftel J, Kirkland E, Lopez A, Schulkin J, Lynfield R: Toxoplasmosis-related knowledge and practices among pregnant women in the United States. Infect Dis Obstet Gynecol. 2003,11 (3): 139-145. 10.1080/10647440300025512.

6. Ogunmodede F, Jones JL, Scheftel J, Kirkland E, Schulkin J, Lynfield R: Listeriosis prevention knowledge among pregnant women in the USA. Infect Dis Obstet Gynecol. 2005, 13 (1): 11-15. 10.1155/2005/734814.

7. Ogunmodede F, Scheftel J, Jones JL, Lynfield R: Toxoplasmosis prevention knowledge among pregnant women in Minnesota. Minn Med. 2005, 88 (2): 32-34.

8. Cates SC, Carter-Young HL, Conley S, O’Brien B: Pregnant women and listeriosis: preferred educational messages and delivery mechanisms. J Nutr Educ Behav. 2004, 36 (3): 121-127. 10.1016/S1499-4046(06)601486.

9. Cannon MJ, Westbrook K, Levis D, Schleiss MR, Thackeray R, Pass RF: Awareness of and behaviors related to child-to-mother transmission of cytomegalovirus. Prev Med. 2012, 54 (5): 351-357. 10.1016/j.ypmed.2012.03.009.

10. Torvaldsen S, Kurinczuk JJ, Bower C, Parsons DE, Roberts CL: Listeria awareness among new mothers in Western Australia. Aust N Z J Public Health. 1999, 23 (4): 362-367. 10.1111/j.1467-842X.1999.tb01276.x.

11. Coonrod DV, Jack BW, Stubblefield PG, Hollier LM, Boggess KA, Cefalo R, Cox SN, Dunlop AL, Hunter KD, Prasad MR, Lu MC, Conry JA, Gibbs RS, Hogan VK: The clinical content of preconception care: infectious diseases in preconception care. Am J Obstet Gynecol. 2008, 199 (6): S296-S309. 10.1016/j.ajog.2008.08.062. Suppl 2. 
12. Cook AJ, Gilbert RE, Buffolano W, Zufferey J, Petersen E, Jenum PA, Foulon W, Semprini AE, Dunn DT: Sources of toxoplasma infection in pregnant women: European multicentre case-control study. European Research Network on Congenital Toxoplasmosis. BMJ. 2000, 321 (7254): 142-147. 10.1136/bmj.321.7254.142.

13. Schmidt DR, Hogh B, Andersen O, Fuchs J, Fledelius H, Petersen E: The national neonatal screening programme for congenital toxoplasmosis in Denmark: results from the initial four years, 1999-2002. Arch Dis Child. 2006, 91 (8): 661-665. 10.1136/adc.2004.066514.

14. Kortbeek LM, Hofhuis A, Nijhuis CD, Havelaar AH: Congenital toxoplasmosis and DALYs in the Netherlands. Mem Inst Oswaldo Cruz. 2009, 104 (2): 370-373. 10.1590/S0074-02762009000200034.

15. Feldman DM, Timms D, Borgida AF: Toxoplasmosis, parvovirus, and cytomegalovirus in pregnancy. Clin Lab Med. 2010, 30 (3): 709-720. 10.1016/j.cll.2010.04.009.

16. Lopez A, Dietz VJ, Wilson M, Navin TR, Jones JL: Preventing congenital toxoplasmosis. MMWR Recomm Rep. 2000, 49 (RR-2): 59-68.

17. Kirkham C, Berkowitz J: Listeriosis in pregnancy: a survey of British Columbia practitioners' knowledge of risk factors, counseling practices, and learning needs. Can Fam Physician. 2010, 56 (4): e158-e166.

18. Doorduyn Y, de Jager CM, van der Zwaluw WK, Wannet WJ, van der Ende A, Spanjaard L, van Duynhoven YT: Invasive Listeria monocytogenes infections in the Netherlands, 1995-2003. Eur J Clin Microbiol Infect Dis. 2006, 25 (7): 433-442. 10.1007/s10096-006-0157-4.

19. Doorduyn Y, de Jager CM, van der Zwaluw WK, Wannet WJ, van der Ende A, Spanjaard L, van Duynhoven YT: First results of the active surveillance of Listeria monocytogenes infections in the Netherlands reveal higher than expected incidence. Euro Surveill. 2006, 11 (4): E060420.4-

20. Kenneson A, Cannon MJ: Review and meta-analysis of the epidemiology of congenital cytomegalovirus (CMV) infection. Rev Med Virol. 2007, 17 (4): 253-276. 10.1002/rmv.535.

21. Cannon MJ, Davis KF: Washing our hands of the congenital cytomegalovirus disease epidemic. BMC Public Health. 2005, 5: 70-10.1186/1471-2458-5-70.

22. de Vries JJ, Korver AM, Verkerk PH, Rusman L, Claas EC, Loeber JG, Kroes AC, Vossen AC: Congenital cytomegalovirus infection in the Netherlands: birth prevalence and risk factors. J Med Virol. 2011,83 (10): 1777-1782. 10.1002/jmv.22181.

23. Raynor BD: Cytomegalovirus infection in pregnancy. Semin Perinatol. 1993, 17 (6): 394-402.

24. Brug J, Assema P, Lechner L: Gezondheidsvoorlichting en gedragsverandering: een planmatige aanpak. Edited by: Open Universiteit Nederland. 2007, Heerlen: van Gorcum, 5

25. Peadon E, Payne J, Henley N, D’Antoine H, Bartu A, O'Leary C, Bower C, Elliott EJ: Attitudes and behavior predict women's intention to drink alcohol during pregnancy: the challenge for health professionals. BMC Public Health. 2011, 11: 584-10.1186/1471-2458-11-584.

26. Giles ML, Pedrana A, Jones C, Garland S, Hellard M, Lewin SR: Antenatal screening practice for infectious diseases by general practitioners in Australia. Aust N Z J Obstet Gynecol. 2009, 49 (1): 39-44. 10.1111/j.1479828X.2008.00932.x.

27. Korver AM, de Vries JJ, de Jong JW, Dekker FW, Vossen AC, Oudesluys-Murphy AM: Awareness of congenital cytomegalovirus among doctors in the Netherlands. J Clin Virol. 2009, 46 (Suppl 4): S11-S15.

28. Kravetz JD, Federman DG: Prevention of toxoplasmosis in pregnancy: knowledge of risk factors. Infect Dis Obstet Gynecol. 2005, 13 (3): 161-165. 10.1080/10647440500068305.

29. Manniën J, Klomp T, Wiegers T, Pereboom M, Brug J, de Jonge A, van der Meijde M, Hutton E, Schellevis F, Spelten E: Evaluation of primary care midwifery in the Netherlands: design and rationale of a dynamic cohort study (DELIVER). BMC Health Serv Res. 2012, 12 (1): 69-10.1186/1472-6963-12-69.

30. CBS Statline. [http://statline.cbs.nl/StatWeb/publication/?DM=SLNL\&PA=70999ned\&D1=0-1,4$\underline{6 \& \mathrm{D} 2}=0,5,10,13-15 \& \mathrm{VW}=\mathrm{T}]$

31. CBS

Statline. [http://statline.cbs.nl/StatWeb/publication/?VW=T\&DM=SLNL\&PA=71822NED\&D1=0\&D2=a\&D3=0\&D4= 1,3-9\&D5=0-2,4,8-10\&D6=0\&D7=1\&HD=081216-1451\&HDR=T,G6,G2,G5,G3\&STB=G1,G4]

32. Gaytant MA, Galama JM, Semmekrot BA, Melchers WJ, Sporken JM, Oosterbaan HP, van Dop PA, Huisman A, Merkus HM, Steegers EA: The incidence of congenital cytomegalovirus infections in The Netherlands. J Med Virol. 2005, 76 (1): 71-75. 10.1002/jmv.20325.

33. Peadon E, Payne J, Henley N, D’Antoine H, Bartu A, O'Leary C, Bower C, Elliott EJ: Women's knowledge and attitudes regarding alcohol consumption in pregnancy: a national survey. BMC Public Health. 2010, 10: 510-10.1186/1471-2458-10-510.

34. Meillier LK, Lund AB, Kok G: Cues to action in the process of changing lifestyle. Patient Educ Couns. 1997, 30 (1): 37-51. 10.1016/S0738-3991(96)00957-3. 
35. Stelma FF, Smismans A, Goossens VJ, Bruggeman CA, Hoebe CJ: Occupational risk of human Cytomegalovirus and Parvovirus B19 infection in female day care personnel in the Netherlands; a study based on seroprevalence. Eur J Clin Microbiol Infect Dis. 2009, 28 (4): 393-397. 10.1007/s10096-008-0635-y.

36. Harvey J, Dennis CL: Hygiene interventions for prevention of cytomegalovirus infection among childbearing women: a systematic review. J Adv Nurs. 2008, 63 (5): 440-450. 10.1111/j.1365-2648.2008.04726.x.

37. Vauloup-Fellous C, Picone O, Cordier AG, Parent-du-Chatelet I, Senat MV, Frydman R, Granger-Keros L: Does hygiene counseling have an impact on the rate of CMV primary infection during pregnancy? Results of a 3-year prospective study in a French hospital. J Clin Virol. 2009, 46 (Suppl 4): S49-S53.

38. Cioffi J, Markham R: Clinical decision-making by midwives: managing case complexity. J Adv Nurs. 1997, 25 (2): 265-272. 10.1046/j.1365-2648.1997.1997025265.x.

39. Kowalski RM, Westen D: Psychology, fourth edition. 2004, New York: John Wiley \& Sons Inc

40. Conyn-van Spaedonck MA, van Knapen F: Choices in preventive strategies: experience with the prevention of congenital toxoplasmosis in The Netherlands. Scand J Infect Dis Suppl. 1992, 84: 51-58.

41. Pawlowski ZS, Gromadecka-Sutkiewicz M, Skommer J, Paul M, Rokossowski H, Suchocka E, Schantz PM: Impact of health education on knowledge and prevention behavior for congenital toxoplasmosis: the experience in Poznan, Poland. Health Educ Res. 2001, 16 (4): 493-502. 10.1093/her/16.4.493.

42. Gollub EL, Leroy V, Gilbert R, Chene G, Wallon M, European Toxoprevention Study Group (EUROTOXO): Effectiveness of health education on Toxoplasma-related knowledge, behavior, and risk of seroconversion in pregnancy. Eur J Obstet Gynecol Reprod Biol. 2008, 136 (2): 137-145. 10.1016/j.ejogrb.2007.09.010. 